\title{
The semantic nature of response competition in the picture-word interference task
}

\author{
STEPHEN J. LUPKER \\ University of Western Ontario, London, Ontario N6A 5C2, Canada
}

\begin{abstract}
Picture-word interference refers to the fact that when a picture (i.e., line drawing) is presented with a word superimposed, picture naming latency is longer than when the picture is presented alone. In addition, naming latency will be further prolonged whenever the word and the picture are members of the same semantic category. This semantic interference effect was investigated in a series of studies in order to develop an appropriate model of the semantic processes involved in picture-word interference. In Experiments 1 and 2, it was determined that the associative strength between the word and the picture is unimportant in the picture-word interference task. In Experiment 3, it was demonstrated that the category typicality of the word and the picture is also unimportant in this task. These results suggest that the semantic processes in picture-word interference would not be well described by a semantic network model. This conclusion was reinforced by Experiment 4, in which it was found that the imageability of a word is a highly important factor in the picture-word interference task. The present set of results suggests that any model of the processes involved in picture-word interference must have at its core the notion of the word's "relevance" to the task of naming the presented picture.
\end{abstract}

From the early research on the Stroop (1935) colorword phenomenon to more recent work by Rayner and Posnansky (1978) and Rosinski (1977), psychologists have used interference paradigms to investigate a wide range of perceptual, cognitive, and response processes. The technique is a simple one. A stimulus having two discrete components is presented to a subject. The subject's task is to respond to one of these components and ignore the other one. Response times in this situation are compared with response times in a control condition in which the stimuli presented involve only the relevant component. If response time differences between conditions are observed, it must be the case that the processing of the irrelevant component somehow interferes with the processing of the relevant one. If not, the two components are, in some sense, thought to be processed independently.

The classic interference paradigm involves the Stroop (1935) color-word phenomenon. The stimuli are words that name colors, printed in incongruent ink colors.

This research was supported by Grant A633 from the Natural Sciences and Engineering Research Council of Canada. A major portion of this paper was reported at the 86th Annual Meeting of the American Psychological Association, Toronto, Ontario, Canada, August 28-September 1, 1978. The author would like to thank Anne Kennedy for her help in the data collection and analyses and Albert Katz for his many helpful suggestions on earlier drafts of this manuscript. Special thanks are owed Joan Symansky, who provided much of the impetus for getting this project off the ground, and Eric Cartman for his continuing assistance in many areas of the present research. Requests for reprints should be sent to Stephen J. Lupker, Department of Psychology, University of Western Ontario, London, Ontario N6A 5C2, Canada
The subject's task is to ignore the word and name the ink color. Typically, response times will be longer than in a control condition in which the stimuli are color patches whose colors are to be named.

Explanations of this phenomenon have centered on two processes, perceptual encoding (Hock \& Egeth, 1970) and response competition (Dyer, 1973; Klein, 1964). The perceptual encoding hypothesis assumes that during encoding the subject must divide his attention between the two stimulus components. Processing of the irrelevant component, the word, delays processing of the color due to a limitation of perceptual resources. Thus, this hypothesis implicates the encoding stage as the locus of the color-word interference.

The response-competition hypothesis is based on the idea that while the subject is actively processing the relevant stimulus component (the color) in order to determine the appropriate response (here, its name), he is also passively (or automatically) processing the irrelevant component (the word). If task-relevant information about the irrelevant component (i.e., the word's name) becomes available before that same information about the color, these two responses will compete for a single motor-output channel. In order to produce the appropriate response, the subject must expend effort to clear this channel by suppressing the response to the word, a process that takes time. Thus, this hypothesis localizes the interference in the response-generation stage.

Dyer (1973), in a review of the Stroop literature, has documented a number of results supporting the response-competition interpretation. On the other hand, evidence for perceptual encoding contributions is much 
less substantial. For example, one result that clearly implicates response-competition processes is Klein's (1964) demonstration that words that named colors were more interfering than color-related words (lemon, grass, fire, sky), which were more interfering than common noncolor-related words (put, take, heart, friend). The perceptual encoding hypothesis must explain these differences purely in terms of the encoding process. That is, it must propose that simultaneous encoding of color words or color-related words somehow hinders the encoding of the color to a greater extent than simultaneous encoding of noncolor-related words. Yet, until the word is encoded, its identity is unknown. It seems quite unreasonable that different categories of words would cause differential amounts of interference if interference were solely due to divided attention during encoding.

On the other hand, Klein's (1964) results are nicely compatible with a response-competition interpretation. Clearing the word's name from the motor-output channel is viewed as an active process. What this process involves is a determination on the part of the subject that the word's name is not the appropriate response. To the extent that the word's name is relevant to the task of naming colors, this determination will be more difficult and, hence, take more time. Words that are color names would have the most relevance to the task and would be expected to produce the most interference. Noncolorrelated words would have the least relevance and could be suppressed quite easily, while color-related words should lead to an intermediate amount of interference. Thus, Klein's results do provide fairly good evidence for the role of response-competition processes in the Stroop task. Additionally, a manipulation such as Klein's appears to be an excellent way to determine the nature of the response-competition processes in this and other interference tasks.

A related interference paradigm has begun to attract attention in recent years. Again, the task is quite simple. A line drawing (i.e., "picture") is presented to a subject with a word superimposed (see Figure 1). The subject's task is to name the picture. Typically, picture naming time is much longer in this condition than in a control condition in which a picture is presented alone. This result is termed the picture-word interference phenomenon.

Within this paradigm, Rosinski (1977) designed a manipulation analogous to that of Klein (1964) and obtained a result that is also very similar. Words in the same semantic category as the picture (e.g., "pig" superimposed on the picture of a dog) cause more interference than words from other semantic categories (e.g., "hat" superimposed on the picture of a dog).

Following the logic outlined above, this result implicates a response-competition explanation of pictureword interference. As such, although Rosinski (1977) does not make the distinction, his explanation of the effect falls into the general class of response-competition hypotheses. Rosinski argues that the locus of the inter-

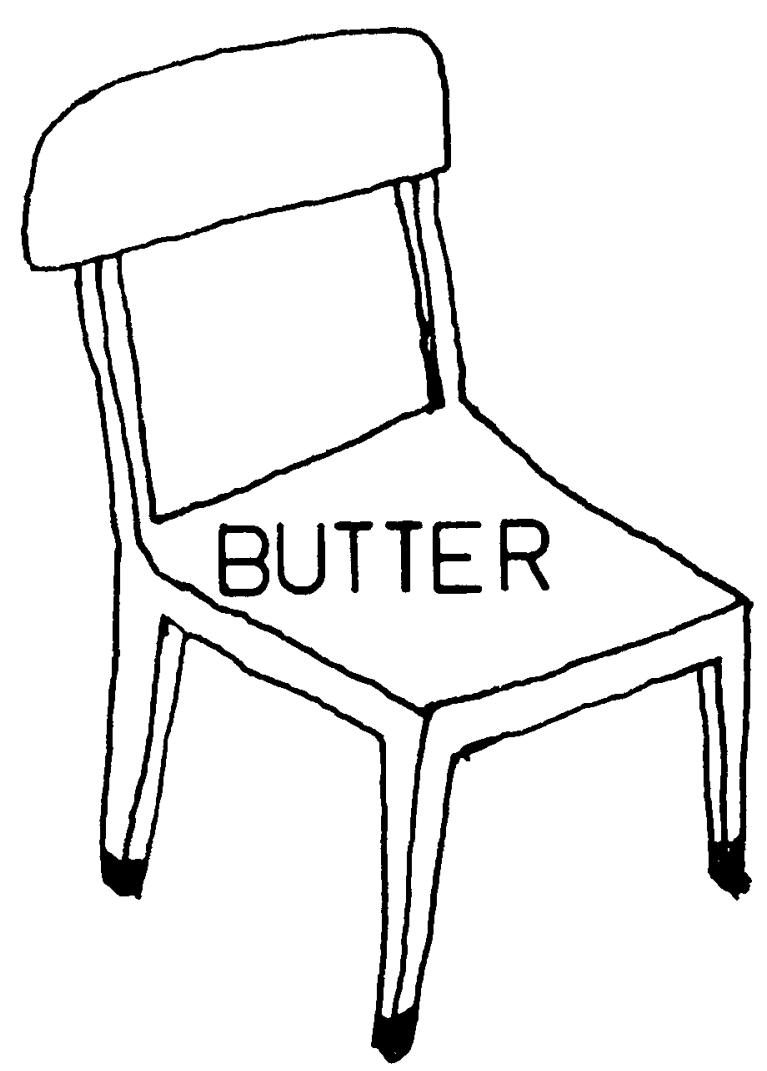

Figure 1. Typical picture-word stimulus.

ference must be a unitary semantic memory system accessed by both verbal and pictorial material. When the picture-word stimulus is presented, the meanings of both stimulus components are accessed in this single semantic memory system. To the extent that these meanings are semantically related, the word's naming response will compete with the picture's naming response, and response time will be prolonged. Thus, a word from the picture's semantic category should cause more interference than an unrelated word.

The semantic interference effect in the pictureword task and Klein's (1964) results in the Stroop task both indicate that more information about the word than simply its name is becoming available to the subject. Because in both situations the subject is actively trying to ignore the word, whatever "semantic" information the word supplies must be, in some sense, primary. That is, it must be information that always becomes available, immediately and automatically, whenever that word is perceived. As such, interference tasks are potentially valuable tools for investigating the nature of information retrieval processes during reading and reading-related activities. Because pictorial stimuli can be used to represent many more concepts than colors, and hence many more dimensions of semantic information, the picture-word interference task seems especially promising in this regard. Thus, the purpose of the present paper is to investigate the semantic interference effect further, to determine what aspects of the word's 
meaning are important factors in this task and to produce an appropriate model of the semantic factors involved in picture-word interference.

\section{EXPERIMENT 1}

The issue addressed in Experiment 1 is whether the semantic interference effect is restricted to situations in which the word and the picture are related by semantic category membership. That is, there are many concepts that are semantically close in the sense that they show a strong associative relationship (e.g., hand-glove, mousecheese) but would not be considered members of the same semantic category. If these kinds of relationships produce as much interference as semantic category relationships, this would imply that the initial semantic information derived from a word is somewhat general in nature. On the other hand, if the semantic interference effect is restricted to semantic category relationships, this would imply that the initial information derived from a word is the kind of information common to members of the word's semantic category.

Using Postman and Keppel's (1970) free association norms, pairs of words were found that were strong bidirectional semantic associates but were not members of the same semantic category. One of these became the word and one the picture in the first condition. The same set of pictures was then used in all other conditions. In Condition 2 the words were all members of the picture's semantic category. In Condition 3 words were used that had no relationship to the pictures on which they appeared. In Condition 4 pronounceable nonwords were used, and in Condition 5 the pictures were presented alone.

The third, fourth, and fifth conditions were included as controls in this and all subsequent experiments. The picture-alone condition serves as a baseline, yielding a measure of how fast the picture can be named in the absence of an interfering component. The interference observed in the pronounceable nonword condition can be attributed to a general distraction due to letters being superimposed on the picture, as well as to interference due to the presence of another pronounceable stimulus component. Beyond this, of course, there should be a large difference in picture naming latency between the pronounceable nonword condition and the condition in which the words are members of the picture's semantic category (Rosinski, 1977). However, words having no relation to the picture seem to create only a little more interference than pronounceable nonwords (Rosinski, 1977).

\section{Method}

Subjects. Twenty University of Western Ontario undergraduate volunteers ( 10 males and 10 females) were paid $\$ 3.50$ to participate in this experiment and Experiment 4 in the same 1-h session. All were native English speakers, and none had ever participated in a picture-word interference experiment before.

Materials and Equipment. Postman and Keppel's (1970) free association norms (Chapters 1, 2, 5, 6, and 7) were consulted in order to discover 11 noun pairs that were strong, bidirectional, semantic associates but did not belong to the same semantic category. In general, these words were the first or second most frequent associates of each other in every set of norms they appeared in. Line drawings ("pictures") were obtained for one member of each pair from a child's coloring book. Five sets of 11 pictures were produced, and each picture was glued on a $23 \times 25.6 \mathrm{~cm}$ card. The five sets of pictures corresponded to the five experimental conditions.

To create Condition 1, the names of the other members of the semantically associated pairs were superimposed on the appropriate pictures in the first picture set (e.g., the picture of a mouse had the word "cheese" superimposed). The second picture set contained names of other members of the picture's semantic category (e.g., the picture of a mouse had the word "dog" superimposed). The categories were quite general (e.g., clothing, four-legged animals), as in Rosinski's (1977) study, and as a rule the words and the pictures in each category showed no strong association according to any of Postman and Keppel's (1970) norms. The third condition, the unrelated word condition, was created by using words from the first two conditions (five from Condition 1, six from Condition 2) and superimposing them on different pictures (e.g., the picture of a mouse had the word "hand" superimposed). The fourth condition involved pronounceable nonwords (e.g., the picture of a mouse had "wydem" superimposed). In the fifth condition, the picturealone condition, no letters appeared on the pictures. (In this and all subsequent experiments, an attempt was made to keep the orthographic and phonetic similarity between the letter string and the name of the picture it appeared on to a minimum.)

Because, unlike in Rosinski's (1977) study, the words in Condition 1, 2, and 3 were not identical, an effort was made to equate the three sets of words on the dimensions of imageability and printed familiarity using Paivio's (Note 1) norms. The words for Condition 1 were, as noted, determined by consulting Postman and Keppel's (1970) free association norms. These words had mean imageability and familiarity ratings of 6.24 and 5.99 , respectively. The words for Condition 2 were selected from Paivio's norms such that their mean imageability and familiarity ratings were the same as for the words in Condition 1 (6.51 and 5.66, respectively). The words in Condition 3 were selected from the set of 22 words making up Conditions 1 and 2 such that their mean imageability and familiarity ratings were the same as for the words in the first two conditions (6.29 and 5.73 , respectively). Additionally, the mean word length in all three conditions and the length of the pronounceable nonwords were approximately the same. The names of the pictures, the words, and the pronounceable nonwords used are reported in the Appendix.

A Gerbrands Model 1-3B-1C three-field tachistoscope was used to present the stimuli. A Hunter Klockounter (Model 120) was used to time the subject's vocal picture naming response. An Electro-Voice, Inc. (Model 621), microphone was positioned approximately $7 \mathrm{~cm}$ away from the subject's mouth. The microphone was connected to a Lafayette Instruments Model 18010 voice-activated relay that stopped the timer at the initiation of the subject's vocal response.

Procedure. Each subject was tested individually. The subjects were informed they would be seeing a series of pictures, some of which would have words superimposed, and their job would be to name the pictures as rapidly as possible without making any mistakes. Initially, the same five pictures (three with words, one with a pronounceable nonword, and one with no letters superimposed) were presented to all subjects as practice to familiarize them with the procedure. None of these pictures or words appeared again in either Experiment 1 or Experiment 4. Next, the 55 stimuli in Experiment 1 were presented sequentially in a random order, each stimulus remaining in view until the subject responded. The response-stimulus interval was used by the experimenter to record the picture naming latency and to reset the equipment for the next trial. Thus, this time was not held 
totally constant but was generally around 5 sec. Errors were recorded, and those pictures were randomly placed back into the set of to-be-presented stimuli.

After responding to all 55 pictures, the subject was given a short (3-min) rest before being presented the 80 stimuli in Experiment 4. After the second session, another short rest was given, and the subject once again responded to the 55 stimuli in Experiment 1 in a different random order. The entire procedure took about $1 \mathrm{~h}$.

\section{Results}

As is typically the case in vocal reaction time tasks, errors were virtually nonexistent (less than $2 \%$ in all conditions). Thus, the few error trials were not analyzed.

The mean correct reaction times for the five conditions are presented in Table 1. Each of these data points is based on 440 observations. As is obvious, the main effect of conditions was highly significant $[F(4,76)=21.12, p<.001] .^{1}$ A subsequent NewmanKeuls analysis at the .05 level revealed that these means could be partitioned into three sets. Reaction times in the picture-alone condition were significantly faster than those in any other condition. Reaction times in the same semantic category condition were slower than those in any other condition. Reaction times in the semantic associate, unrelated word, and pronounceable nonword conditions were indistinguishable, although, as anticipated, reaction times in the pronounceable nonword condition were slightly faster than the reaction times in the other two conditions.

Finally, the main effect of trial block was also significant $[F(1,19)=17.21, p<.001]$, indicating that subjects improved with practice. However, this factor did not interact with conditions $(\mathrm{F}<1.0)$.

\section{Discussion}

Results for the four basic conditions of Experiment 1 were exactly as expected. Both unrelated words and pronounceable nonwords led to longer reaction times than the pictures alone, with unrelated words causing slightly more interference than pronounceable nonwords. Words from the picture's semantic category were even more interfering, yielding reaction times approximately $30 \mathrm{msec}$ longer than those of unrelated words. The major result, however, is that words having a strong associative relationship to the picture caused exactly the same amount of interference as unrelated words. Thus, it appears that the semantic interference effect is restricted to semantic category membership.

This result indicates that the semantic processes involved in the picture-word interference task are somewhat different from those involved in the classic tasks used to study semantic memory (e.g., Collins \& Quillian, 1969; Conrad, 1972; Fischler, 1977; Meyer \& Schvaneveldt, 1971). For example, Meyer and Schvaneveldt have demonstrated that when a subject is required to make a lexical (word-nonword) decision about a letter string, he responds to words faster when he has just seen a semantically associated word. Fischler (1977) extended this finding by showing that a relatively unassociated word from the same semantic category could also facilitate a subsequent word-nonword decision. Thus, unlike in the present study, it is the existence of a semantic relationship rather than the type of relationship that is important in the lexical decision task.

Results from the lexical decision task, as well as results from related tasks, have been interpreted by Collins and Loftus (1975) as support for a network model of semantic memory. Each concept in memory is represented as a node, with semantically related concept nodes connected to each other by relational links. When a node is accessed by presenting the appropriate word, activation spreads out to related nodes, facilitating the processing of these concepts. This spread of activation is assumed to be very rapid, since facilitation has been found with stimulus onset asynchronies as brief as $40 \mathrm{msec}$ (Fischler \& Goodman, 1978). It is presumably through this spreading activation process that, at least, the initial information is gained about the concept whose node was originally accessed.

While the present study differs from most studies involving semantic memory in that a semantic relationship leads to inhibition rather than to facilitation, a memory structure like that proposed by Collins and Loftus (1975) may serve as an adequate model of the process. That is, whenever a word or a picture is perceived, the appropriate node is accessed in memory. Whenever

Table 1

Mean Reaction Times (RT) in Milliseconds as a Function of Experimental Conditions in Experiments 14

\begin{tabular}{|c|c|c|c|c|c|}
\hline & RT & $\begin{array}{c}\text { Example } \\
\text { Word }\end{array}$ & & RT & $\begin{array}{c}\text { Example } \\
\text { Word }\end{array}$ \\
\hline \multicolumn{3}{|c|}{ Experiment 1 (Example Picture: Mouse) } & \multicolumn{3}{|c|}{ Experiment 3 (Example Picture: Foot) } \\
\hline $\begin{array}{l}\text { Same Semantic Category } \\
\text { Frequent Associate } \\
\text { Unrelated Word } \\
\text { Pronounceable Nonword } \\
\text { Picture Alone }\end{array}$ & $\begin{array}{l}811 \\
778 \\
779 \\
766 \\
687\end{array}$ & $\begin{array}{l}\text { dog } \\
\text { cheese } \\
\text { hand } \\
\text { lorim }\end{array}$ & $\begin{array}{l}\text { Typical Category Member } \\
\text { Atypical Category Member } \\
\text { Unrelated Word } \\
\text { Pronounceable Nonword } \\
\text { Picture Alone }\end{array}$ & $\begin{array}{l}734 \\
740 \\
710 \\
705 \\
643\end{array}$ & $\begin{array}{l}\text { arm } \\
\text { lip } \\
\text { singer } \\
\text { gadid }\end{array}$ \\
\hline \multicolumn{3}{|c|}{ Experiment 2 (Example Picture: Hand) } & \multicolumn{3}{|c|}{ Experiment 4 (Example Picture: Butterfly) } \\
\hline $\begin{array}{l}\text { Frequent Associate/Same Semantic Category } \\
\text { Same Semantic Category } \\
\text { Unrelated Word } \\
\text { Pronounceable Nonword } \\
\text { Picture Alone }\end{array}$ & $\begin{array}{l}771 \\
771 \\
742 \\
720 \\
660\end{array}$ & $\begin{array}{l}\text { foot } \\
\text { ankle } \\
\text { table } \\
\text { cokem }\end{array}$ & $\begin{array}{l}\text { Highly Imageable Word } \\
\text { Nonimageable Word } \\
\text { Pronounceable Nonword } \\
\text { Picture Alone }\end{array}$ & $\begin{array}{l}825 \\
801 \\
771 \\
712\end{array}$ & $\begin{array}{l}\text { newspaper } \\
\text { law } \\
\text { pilos }\end{array}$ \\
\hline
\end{tabular}


these nodes are semantically linked, some sort of interaction can take place between them. In a lexical decision task, in which both words are important to the final response, this interaction may facilitate a response. However, in the present task, where only one of the two inputs is important to the final response, this interaction may instead inhibit the appropriate response. For example, because the word's name is available before the picture's name (Fraisse, 1968), this interaction may serve only to increase the viability of the word's name as a response, causing it to be more interfering. Thus, it would be possible to explain Rosinski's (1977) original results within the framework of a semantic network model. What the present study has indicated is that, if this type of framework is an appropriate model of semantic memory, links between associated concepts not belonging to the same semantic category are functionally unimportant in picture-word interference. The purpose of Experiment 2 was to determine whether associative strength is at all important in the picture-word interference task.

\section{EXPERIMENT 2}

Rips, Shoben, and Smith (1973) and Rosch (1975) have demonstrated that even within a semantic category there are reliable effects of "semantic distance" between concepts. In order to account for these results, Collins and Loftus (1975) have postulated that the strength of association between two concepts is reflected in the strength of the relational link between them. Thus, highly associated concepts (e.g., cat-dog) would be semantically "closer" than less related concepts (e.g., cat-horse) due to the strengths of the respective links in semantic memory. In Experiment 2, the question asked was whether the strength of the link between concept nodes for two members of the same semantic category, as measured by associative strength, is an important factor in picture-word interference. That is, would nodes that are semantically close interact to a greater extent and produce a longer picture naming latency than nodes that are less strongly linked?

\section{Method}

Subjects. Twenty University of Western Ontario undergraduate volunteers (6 males and 14 females) received course credit to appear in this experiment and another, unrelated experiment in the same $1-\mathrm{h}$ session. All were native English speakers, and none had ever participated in a picture-word interference experiment before.

Materials and Equipment. Postman and Keppel's (1970) free association norms (Chapters $1,2,5,6$, and 7) were consulted in order to discover nine noun pairs that were strong, bidirectional, semantic associates that belonged to the same semantic category. Again, in general, these words were the first or second most frequent associate of each other in every set of norms they appeared in. Line drawings were again obtained for one member of each pair from a child's coloring book. Five sets of the nine pictures were produced, and each picture was glued on a $23 \times 25.6 \mathrm{~cm}$ card. The five sets of pictures corresponded to the five experimental conditions.
To create Condition 1 , the names of the other members of the strongly associated pairs were superimposed on the appropriate pictures in the first picture set. The second picture set contained names of other members of the picture's semantic category which showed no associative relationship to the picture. The third condition, the unrelated word condition, was created by using words from the first two conditions (four from Condition 1, five from Condition 2) and superimposing them on different pictures. The fourth condition involved pronounceable nonwords. In the fifth condition, the picture-alone condition, no letters appeared on the picture.

Again, because the words in Conditions 1,2, and 3 were not identical, an effort was made to equate the three sets of words on the dimensions of imageability and printed familiarity using Paivio's (Note 1) norms. The words for Condition 1 were, as noted, determined by consulting Postman and Keppel's (1970) free association norms. These words had mean imageability and familiarity ratings of 6.47 and 6.38 , respectively. The words for Condition 2 were selected from Paivio's norms such that their mean imageability and familiarity ratings were the same as for the words in Condition 1 (6.44 and 6.15, respectively). The words in Condition 3 were selected from the set of 18 words making up Conditions 1 and 2 such that their mean imageability and familiarity ratings were the same as for the words in the first two conditions (6.46 and 6.21 , respectively). Additionally, the mean word length in all three conditions and the length of the pronounceable nonwords were approximately the same. The names of the pictures, the words, and the pronounceable nonwords used are reported in the Appendix.

The tachistoscope, timer, microphone, and voice-activated relay were the same as used in Experiment 1 .

Procedure. The procedure was almost identical to that of Experiment 1. Again, the subjects were told to name the pictures as rapidly and accurately as possible, and then they were given a brief practice session. The subjects then responded to each of 45 stimuli in Experiment 2 in a random order. Following a brief rest, they next responded to each of the stimuli in another, unrelated experiment. Following another brief rest, they again responded to the stimuli in Experiment 2 in a different random order. Again, errors were recorded, and those pictures were randomly placed back into the set of to-be-presented pictures. As before, the entire procedure took about $1 \mathrm{~h}$.

\section{Results}

The mean correct reaction times for the five conditions in Experiment 2 are presented in Table 1. Each of these data points is based on 360 observations. Just as in Experiment 1, errors were virtually nonexistent, so error trials were not analyzed. The main effect of conditions was highly significant $[F(4,76)=25.19$, $p<.001]$. A Newman-Keuls analysis at the .05 level revealed that these means could be partitioned into three sets. Reaction times in the picture-alone condition were faster than those in any other condition. Reaction times in the pronounceable nonword and unrelated word conditions were indistinguishable, although reaction times in the pronounceable nonword condition were somewhat faster than reaction times in the unrelated word condition. Finally, reaction times in the two semantic category conditions were slower than reaction times in all other conditions (again, approximately $30 \mathrm{msec}$ slower than those in the unrelated word condition) and were virtually identical to each other.

The main effect of trial block was once again significant $[F(1,19)=38.58, p<.001]$ but did not interact with conditions $[F(4,76)=1.13$, n.s.] 


\section{Discussion}

The results of Experiment 2 were quite clear-cut. Once again, unrelated words and pronounceable nonwords led to longer reaction times than did pictures alone, with unrelated words being slightly more interfering than pronounceable nonwords. Once again, unassociated words from the picture's semantic category led to a further elevation of reaction times by approximately $30 \mathrm{msec}$. The major result, however, is that the mean reaction time in the associated category member condition was exactly the same as in the unassociated category member condition and $30 \mathrm{msec}$ longer than in the unrelated word condition. Thus, as before, the strength of association between the word and the picture had absolutely no influence on reaction times.

This result, together with that of Experiment 1, suggests that either (1) within-category semantic distance is functionally unimportant in a task of this sort or (2) associative strength is not an adequate measure of semantic distance. In terms of the network model of semantic memory, acceptance of the latter conclusion would merely put an uncomfortable restriction on the nature of the relational links in semantic memory. However, acceptance of the former conclusion would essentially obviate the use of a network model in describing the processes involved in picture-word interference. So, in view of the rapidly growing literature detailing semantic distance effects, an alternative definition of semantic distance was sought.

\section{EXPERIMENT 3}

One alternative way of conceptualizing semantic distance has recently been suggested by Rosch (1975). Rosch has proposed that each semantic category has a central representation in which the core meaning of the category is depicted. This representation could be thought of as being a "most typical" category member. Semantic distance would be defined in terms of a real category member's distance from this central core meaning. Members highly typical of a particular category (e.g., banana and peach would be typical fruits) would be semantically close, while the semantic distance between a typical member and an atypical member would be much larger (e.g., banana and lime).

For Experiment 3 semantic distance was redefined, in terms of typicality, and, once again, the question addressed was whether within-category semantic distance is an important factor in picture-word interference. Because of the limitations imposed by the requirement that the typical and atypical category members be equated on dimensions of imageability and familiarity, the typicality norms provided by Rosch (1975) were too restrictive. Instead, typicality was defined in terms of Battig and Montague's (1969) production norms. The assumption made here is that the more typical an object is, the more likely it is that the object will be generated in response to the category name (cf. Mervis, Catlin, \& Rosch, 1976, who have shown that the correlation between Battig \& Montague's norms and Rosch's norms is at least .50). Ten pictures were used, all representing fairly typical category members. In Condition 1 the names of other highly typical category members were superimposed on the appropriate pictures. In Condition 2 the names of atypical category members were used. Condition 3 was again the unrelated word condition; Condition 4 , the pronounceable nonword condition; and Condition 5 , the picture-alone condition.

\section{Method}

Subjects. Twenty University of Western Ontario undergraduate volunteers ( 8 males and 12 females) received course credit to appear in this experiment and another, unrelated experiment in the same 1-h session. All were native English speakers, and none had ever participated in a picture-word interference experiment before.

Materials and Equipment. Battig and Montague's (1969) production norms were consulted to find 10 words with relatively high production frequencies in their particular semantic category that could be unambiguously represented as line drawings. (The mean production frequency of these words was 234.) Line drawings were then obtained for each of these words from a child's coloring book. Five sets of the 10 pictures were produced, and each picture was glued on a $23 \times 25.6 \mathrm{~cm}$ card. The five sets of pictures corresponded to the five experimental conditions.

For each picture, two words were selected from Battig and Montague's (1969) norms such that one of the words had a relatively high production frequency (typical category members) and the other member had a relatively low production frequency (atypical category members). (The mean production frequencies were 260 and 26, respectively.) Condition 1 was created by superimposing the highly typical category members on the appropriate pictures. Condition 2 was created by superimposing the atypical category members on their appropriate pictures. The third condition, the unrelated word condition, was created by using words from the first two conditions (five from Condition 1, five from Condition 2) and superimposing them on different pictures. The fourth condition again involved pronounceable nonwords, and the fifth condition, the pictures alone.

An additional restriction on the selection of typical and atypical category members was that they be equated on dimensions of imageability, familiarity, and, because the data were available, meaningfulness using Paivio's (Note 1) norms. The relevant ratings were $6.45,5.85$, and 6.56 for Condition 1 ; $6.33,5.33$, and 6.75 for Condition 2; and 6.40, 5.52, and 6.69 for Condition 3. Again, mean word length in all three conditions and the length of the pronounceable nonwords were approximately the same. The names of the pictures, the words, and the pronounceable nonwords used are listed in the Appendix.

The tachistoscope, timer, microphone, and voice-activated relay were the same as those used in the previous experiments.

Procedure. The procedure was exactly identical to that of Experiment 2 . Subjects were told to name the pictures as rapidly and accurately as possible, and then they were given a brief practice session. They then responded to each of the 50 stimuli in Experiment 3 in a random order. Following a brief rest, they next responded to each of the stimuli in another, unrelated experiment. Following another brief rest, they again responded to the 50 stimuli in Experiment 3 in a different random order. Again, errors were recorded, and those stimuli were placed back into the set of to-be-presented stimuli. The entire procedure took about $1 \mathrm{~h}$.

\section{Results}

Again, errors were virtually nonexistent (less than 
$2 \%$ of the trials in each condition), so error trials were not analyzed. The mean correct reaction times for the five conditions in Experiment 3 are presented in Table 1. Each of these data points is based on 400 observations. The main effect of conditions was highly significant $[F(4,76)=37.36, p<.001]$. A Newman-Keuls analysis at the .05 level revealed that, as in Experiment 2, these means could be partitioned into three sets. The first set contained only the picture-alone condition. Reaction times in this condition were faster than those in any other condition. The second set contained the pronounceable nonword and unrelated word conditions. The third set contained the two semantic category conditions, with these two conditions again yielding reaction times $25-30 \mathrm{msec}$ longer than those in the unrelated word condition. Thus, there is no evidence for a semantic distance effect. In fact, the slight difference between the two semantic category conditions was in the opposite direction.

Again, the main effect of trial block was significant $[F(1,19)=38.16, p<.001]$ but did not interact with conditions $(\mathrm{F}<1.0)$.

\section{Discussion}

Again, the results were quite clear-cut. The relationships among the three basic conditions were as before. Pictures were named most rapidly when no letters were superimposed, and unrelated words caused only slightly more interference than pronounceable nonwords. Most importantly, typical category members caused no more picture naming interference than less typical category members. Thus, as in Experiment 2, there was no evidence of a semantic distance effect.

It may be argued that the atypical instances used in Experiment 3 did not represent truly atypical instances of their particular categories, and if truly atypical instances had been used, a semantic distance effect would have obtained. The crucial point, however, is that these stimuli are representative of the kinds of stimuli used by Rosch (1975) and others to produce semantic distance effects in related paradigms. Thus, if semantic distance is a useful construct for describing the processes involved in picture-word interference, its effects should have manifested themselves in Experiment 3. The fact that this did not occur in either Experiment 3 or Experiment 2, in which another kind of semantic distance was investigated, does lead to the conclusion that semantic distance is of little importance in picture-word interference.

\section{EXPERIMENT 4}

The network model of semantic memory derives from the desire to represent the existence and strength of interrelations between concepts in memory. In Experiment 1, it was demonstrated that only certain of these interrelations are important in picture-word interference. In Experiments 2 and 3, it was demon- strated that the strengths of the important interrelations are also essentially irrelevant to the picture-word interference task. Thus, although the network model is a useful heuristic for explaining the results from many related tasks, the present results indicate that it is not an appropriate model for describing the semantic processes involved in picture-word interference.

Alternatively, the semantic processes involved in picture-word interference might be explained in much the same way as Klein's (1964) results in the Stroop task were explained, in terms of a more basic type of response-competition process. The names of the two stimulus components (the word and the color, or the word and the picture) must compete for a single motoroutput channel. In order to produce the appropriate response, the subject must suppress the response to the word in order to clear the channel for the relevant response. This suppression is especially difficult in the Stroop task because the words are color names, and hence, potential responses. Thus, they are quite relevant to the task's demands. When words of less relevance are used, for example, noncolor words or color words whose ink color never appears in the experiment, less interference is found.

As applied to our task, this explanation would suggest that when a picture is presented with a word superimposed, first the word's name and then the picture's name become available and begin competing for the single output channel. Over time, additional information about the two competing responses also becomes available. In order to suppress the response to the word, the subject must first determine which of the two available responses is appropriate to the presented picture. To the extent that the information about the word disqualifies it as the appropriate response, the word will be easier to suppress. Thus, picture naming latency would be purely a function of the word's relevance to the appropriate response. The easier it is for the subject to determine that the word's name is not the appropriate response to the presented picture, the shorter the reaction time will be.

As demonstrated in Experiment 1, a strong associative relationship between two concepts not belonging to the same semantic category (e.g., mouse-cheese) should be unimportant in this task. A picture of a mouse could no more represent a cheese than it could a table. Thus, the word "cheese" is no more relevant to the task of naming the picture of a mouse than is an unrelated word like "table," and it should cause no additional interference. On the other hand, members of the same semantic category, even somewhat distant ones, are similar in many ways. In particular, they are probably quite similar in the kind of information that is initially available whenever those words are perceived. So, a word like "painter" would be just as relevant to a picture of a nurse as an associated category member like "doctor" or a highly typical category member like "teacher." Thus, as demonstrated in Experiments 2 and 
3 , the stimuli that give rise to the standard semantic distance effects in more typical paradigms should not produce those same types of effects here.

The present test of the response-relevance hypothesis is a quite simple one. In line with the logic just outlined, the one piece of information about a word that makes it relevant to the task at all is its ability to be drawn. So, if response relevance is the important factor in picture-word interference, a word like "law" that cannot be drawn should be suppressed quite easily in comparison with a very concrete word like "newspaper." On the other hand, a model of picture-word interference based on semantic networks would not predict any difference between the amount of interference generated by "law" and the amount of interference generated by "newspaper."

\section{Method}

Subjects. The subjects were the same as in Experiment 1 . Materials and Equipment. Twenty line drawings were selected from a child's coloring book. Four sets of these 20 pictures were then produced and glued on $23 \times 25.6 \mathrm{~cm}$ cards. The four sets of pictures corresponded to the four experimental conditions.

Paivio's (Note 1) norms were then used to select 20 words rated high in imageability (mean rating 6.65) and 20 words rated low in imageability (mean rating 3.33 ) that had equivalent ratings on printed familiarity (6.02 and 6.05, respectively) and meaningfulness (6.20 and 6.25 , respectively). The highly imageable words were, of course, quite easy to draw, while in all cases the nonimageable words were essentially impossible to represent as a picture. As before, mean word length for the two sets of words and the length of the pronounceable nonwords were approximately the same. (Again, the names of the pictures, the words, and the pronounceable nonwords used are listed in the Appendix.) Condition 1 was created by superimposing the 20 highly imageable words on one set of the 20 pictures. Condition 2 was created by superimposing the 20 nonimageable words on another set of the 20 pictures. In both cases, care was taken to make sure that no word was semantically related to the picture on which it appeared. The third condition involved pronounceable nonwords, and the fourth condition, the pictures alone.

The tachistoscope, timer, microphone, and voice-activated relay were the same as those used in the previous experiments.

Procedure. The basic procedure was the same as in all previous experiments. The only difference was that each subject saw the full set of 80 pictures only once. As described earlier, this experiment was run in conjunction with Experiment 1 . After receiving the instructions and a brief practice session, the subjects first responded to the 55 stimuli in Experiment 1. After a short rest, they responded to the 80 stimuli in Experiment 4 in a random order. After another rest, they once again responded to the 55 stimuli in Experiment 1.

\section{Results}

As before, errors were virtually nonexistent, so error trials were not analyzed. The mean correct reaction times for the four conditions in Experiment 4 are presented in Table 1. Each of these data points is based on 400 observations. The main effect of conditions was again highly significant $[F(3,57)=33.88, p<.001]$. A Newman-Keuls analysis at the .05 level revealed that each condition was significantly different from all other conditions. In particular, reaction times in the imageable word condition were significantly longer than those in the nonimageable word condition.

\section{Discussion}

The major result of Experiment 4 was that words that are highly imageable and, hence, can be represented as pictures were much more interfering than nonimageable words in the picture-word interference task. This result nicely supports the response-relevance hypothesis. Imageable words, because they represent potential responses, should be more relevant to the task's demands and, therefore, should cause more picture-naming interference than do nonimageable words. On the other hand, this result seems to be quite incompatible with any semantic network explanation of the processes involved in picture-word interference. Neither the imageable nor the nonimageable words had any semantic relationship to the pictures on which they appeared. Thus, there would be no reason to expect differential amounts of interference in the two word conditions. So, when taken together with the results of the first three experiments, the present results indicate that any model of the processes involved in picture-word interference must have at its core the notion of response relevance.

The other noteworthy result of Experiment 4 is that for the first time there is a significant difference between the two word conditions and the pronounceable nonword condition. Using the picture-alone condition as a baseline, it appears that this difference is not a result of using less interfering pronounceable nonwords in Experiment 4. The 59-msec difference between the picture-alone and pronounceable nonword conditions in Experiment 4 is quite similar to the $60-$ to $79-\mathrm{msec}$ differences between these same conditions in the first three experiments. Instead, this result seems to be due to inflated reaction times in the two word conditions in Experiment 4. That is, the words used in the highly imageable condition in Experiment 4 were only slightly different from the words used in the unrelated word conditions in the first three experiments on the dimensions of imageability and familiarity. Yet the $113-\mathrm{msec}$ difference between the highly imageable condition and the picture-alone condition in Experiment 4 is somewhat larger than the 67. to 92-msec differences between the unrelated word and picture-alone conditions in the first three experiments. Thus, the question seems to be, why was the absolute amount of interference in the two word conditions in the last experiment $21-46 \mathrm{msec}$ greater than that in similar conditions in other experiments?

There seem to be three differences between the first three experiments and the final experiment, and each may be partly responsible for this result. First, subjects saw each stimulus in Experiment 4 only once, while in Experiments 1,2, and 3 they responded to each stimulus twice. Certainly, the second exposure of a stimulus is easier to respond to, as is indicated by the 
significant effect of trials in the first three experiments. Additionally, regardless of the lack of a Trials by Conditions interaction, the difference between the unrelated word condition and the picture-alone condition did decrease on the second set of trials by about $20 \mathrm{msec}$ in all three experiments. Thus, it is likely that a second exposure to the stimuli in Experiment 4 would have reduced the difference between the picture-alone condition and the two word conditions by about $10 \mathrm{msec}$.

A second difference is that every word in the unrelated word conditions of Experiments 1,2, and 3 was also used in one of the other conditions. Thus, each word in these conditions appeared on two stimuli in each stimulus set. The second presentation of a word, even on a different picture, may reduce the amount of interference caused by that word. Since, on the average, half the words in the unrelated word conditions of the first three experiments would have been seen first on another picture, this may have artificially reduced subjects' reaction times.

By the same token, on the average, only a quarter of the words used in the semantic conditions would have been seen first on another picture and would also have artificially lower reaction times. Therefore, because this problem would affect more stimuli in the unrelated word condition than in the semantic category condition, the implication would be that the actual difference between these two conditions is less than the $30 \mathrm{msec}$ found in Experiments 1, 2, and 3. However, based on unpublished experiments conducted in the author's laboratory in which (1) entirely different sets of words were used in the semantic category and unrelated word conditions and (2) exactly the same set of words was used in the two conditions but on different pictures, $30 \mathrm{msec}$ seems to be quite an accurate estimate of the difference between these two conditions. So, while it is possible that creating the unrelated word condition from the two semantic conditions in the first three experiments may have reduced the reaction time for this condition slightly, its contribution to the overall pattern of results is probably minimal.

Finally, the third difference between Experiment 4 and Experiments 1,2, and 3 is the length of the letter strings used. The words used in Experiment 4 contained, on the average, one more letter and one-half more syllable than the words in the first three experiments. If either of these factors served to slow down the generation of the word's name, it may have also slowed down the beginning of the suppression process and led to a longer reaction time. While such an effect may be on the order of, perhaps, only $10 \mathrm{msec}$, it may also account for part of the difference between the results of Experiment 4 and the first three experiments.

This final explanation is weakened, of course, by the fact that the longer pronounceable nonwords used in Experiment 4 did not also cause slightly more interference than the pronounceable nonwords in Experiments 1, 2, and 3. However, the amount of time necessary to suppress a nonword probably varies as a function of many things, for example, its orthographic regularity and pronounceability. In the present set of experiments, although all the pronounceable nonwords were easily pronounced, no attempt was made to control for any factors other than length. Thus, it is not surprising that there should be no difference in the amount of interference caused by the six-letter pronounceable nonwords in Experiment 4 and the five-letter pronounceable nonwords in the first three experiments.

\section{GENERAL DISCUSSION}

\section{The Model}

The present set of experiments represented an attempt to explore the semantic processes involved in pictureword interference in order to produce an appropriate model of those processes. The framework for the model being proposed is a logical extension of a reading model offered by Theios and Muise (1976). Memory is viewed as a set of locations, each corresponding to a particular concept. Each location is regarded as a file containing relevant information about that particular concept (e.g., its name, its semantic category, etc.). Both words and pictures may access these files and allow retrieval of whatever information is relevant to the task being engaged in.

In the picture-word interference task, both the word and the picture cause the subject to access their respective files and retrieve whatever information is available. Because naming words is such an overlearned response, the word's name will be one of the first pieces of information to come out of its file. Other, semantic information will soon follow. The picture may or may not allow access to the relevant memory location as rapidly as the word (cf. Banks \& Flora, 1977). However, more importantly, accessing a location through a picture will not allow retrieval of the concept's name as rapidly as accessing through the word. Thus, by the time the pic. ture's name is retrieved, the word's name will already be available, setting up a competition situation.

At this point, subjects will have two potential responses at their disposal and must decide which is appropriate to the presented picture. Also available at this point are other pieces of information about both of these concepts that have become available from the respective files. In neither case was this information actively retrieved from the files. Thus, it can be regarded as primary information, that is, information that always becomes available whenever a word's or a picture's name is retrieved. To the extent that the information in the word's file promotes the word's name as a potential response, it will be difficult for the subject to determine which of the two responses to make. In the present set of experiments, it was shown that a word's naming response can be relevant either in general-because the word can be represented as a picture-or specificallybecause the word may be a potentially appropriate name for the presented picture. This type of specific relevance was presumably derived from the fact that much of the 
primary information available about a word is common to nearly all members of the word's semantic category. Thus, there will be a substantial overlap between the information available from the word's file and the information available about the picture. The general relevance caused by imageability may have been derived in any of a number of ways. For example, part of the primary information available from an imageable word may be its image. Retrieval of the image may necessitate a comparison between it and the presented picture, a process unnecessary with nonimageable words. Alternatively, part of the primary information available about nonimageable words may relate to a lack of concrete physical features. Perhaps, as soon as information of this sort is retrieved, a very rapid response determination can be made. In any case, when this determination is finally made, the subject is then free to complete the suppression process, clearing the motoroutput channel for the appropriate response.

\section{Unitary vs. Dual Coding}

Rosinski (1977) has claimed that the fact that words can interfere with the processing of pictures is evidence for the existence of a unitary semantic memory system accessed by both verbal and pictorial material. The model discussed above is also based on the notion of a unitary memory system accessed by both words and pictures. However, it is not true that either the pictureword phenomenon or the semantic interference effect denies the existence of two memory systems, one accessed by verbal material and the other accessed by pictorial material (e.g., Paivio, 1971). Nor is a dual store interpretation at all incompatible with the present model.

Initially, the picture may allow access only to a pictorial memory system that provides certain pictorially based information. However, in order to determine the picture's name, the appropriate location in verbal memory must also be accessed. The word, of course, would allow direct access to the verbal store so that its name as well as other more verbally based information will, at this point, already be available. In any case, at the point at which both names are finally available, the two responses can compete with each other just as the model states, producing both the picture-word interference phenomenon and the semantic interference effect. Thus, a dual memory system would be quite compatible not only with the basic phenomena, but also with the model proposed earlier.

\section{Conclusion}

The purpose of the present paper was to examine the role of semantic factors in picture-word interference and to produce an appropriate model of the processes involved. The model proposed follows quite closely a generally accepted explanation of the Stroop colorword phenomenon. That is, both color-word and pictureword interference seem to result from responsecompetition processes, with the relevance of the word to the task's demands being the critical variable. Thus, it appears that these two effects may really be nothing more than two sides of the same coin.

\section{REFERENCE NOTE}

1. Paivio, A. Imagery and familiarity ratings for 2,448 words: Unpublished norms. Unpublished manuscript, Department of Psychology, University of Western Ontario.

\section{REFERENCES}

Banks, W. P., \& Flora, J. Semantic and perceptual processes in symbolic comparisons. Journal of Experimental Psychology: Human Perception and Performance, 1977, 3, 278-290.

Battig, W. F., \& Montague, W. E. Category norms for verbal items in 56 categories: A replication and extension of the Connecticut category norms. Journal of Experimental Psychology Monograph, 1969, 80(3, Pt. 2).

Clark, H. H. The language-as-fixed-effect fallacy: A critique of language statistics in psychological research. Journal of Verbal Learning and Verbal Behavior, 1973, 12, 335-359.

Collins, A. M., \& Lortus, E. F. A spreading-activation theory of semantic processing. Psychological Review, 1975, 82, 407-428.

Collins, A. M., \& Quillian, M. R. Retrieval time from semantic memory. Journal of Verbal Learning and Verbal Behavior, $1969,8,240-248$.

ConRaD, C. Cognitive economy in semantic memory. Journal of Experimental Psychology, 1972, 92, 149-154.

DYER, F. N. The Stroop phenomenon and its use in the study of perceptual, cognitive, and response processes. Memory \& Cognition, 1973, 1, 106-120.

Fischler, I. Semantic facilitation without association in a lexical decision task. Memory \& Cognition, 1977, 5, 335-339.

Fischler, I., \& GoOdman, G. O. Latency of associative activation in memory. Journal of Experimental Psychology: Human Perception and Performance, 1978, 4, 455-470.

Fraisse, P. Motor and verbal reaction times to words and drawings. Psychonomic Science, 1968, 12, 235-236.

Носк, H. S., \& EGETH, H. E. Verbal interference with encoding in a perceptual classification task. Journal of Experimental Psychology, 1970, 83, 299-303.

KLEIN, G. S. Semantic power measured through the interference of words with color-naming. American Journal of Psychology, 1964, 77, 576-588.

Mervis, C. B., Catlin, J., \& Rosch, E. Relationship among goodness-of-example, category norms, and word frequency. Bulletin of the Psychonomic Society, 1976, 7, 283-284.

Meyer, D. E., \& Schvaneveldt, R. W. Facilitation in recognizing pairs of words: Evidence of a dependence between retrieval operations. Journal of Experimental Psychology, 1971, 90, 227-234

Paivio, A. Imagery and verbal processes. New York: Holt, Rinehart, \& Winston, 1971.

Postman, L., \& Keppel, G. (Eds.). Norms of word association. New York: Academic Press, 1970.

Rayner, K., \& Posnansky, C. Stages of processing in word identification. Journal of Experimental Psychology: General, $1978,107,64-80$.

Rips, L. J., Shoben, E. J., \& Smith, E. E. Semantic distance and the verification of semantic relations. Journal of Verbal Learning and Verbal Behavior, 1973, 12, 1-20.

Rosch, E. Cognitive representations of semantic categories. Journal of Experimental Psychology: General, 1975, 104, 192-233.

Rosinski, R. R. Picture-word interference is semantically based. Child Development, 1977, 48, 643-647.

Stroop, J. R. Studies of interference in serial verbal reactions. Journal of Experimental Psychology, 1935, 18, 643-662.

Theios, J., \& Muise, J. G. The word identification process in reading. In N. J. Castellan, Jr., \& D. Pisoni (Eds.), Cognitive theory (Vol. 2). Potomac, Md: Erlbaum, 1976. 
Wike, E. L., \& Church, J. D. Comments on Clark's "The language-as-fixed-effect fallacy." Journal of Verbal Learning and Verbal Behavior, 1976, 15, 249-255.

\section{NOTE}

1. Due to the arguments presented by Wike and Church (1976) and others, stimulus materials was not treated as a random factor as prescribed by Clark (1973) in this or any subsequent analysis. Any questions of generalizability that may be raised can be answered by noting that remarkably similar results were obtained in the first three experiments with quite different sets of stimuli.

\begin{tabular}{|c|c|c|c|c|}
\hline \multicolumn{5}{|c|}{ Appendix } \\
\hline \multirow[b]{2}{*}{ Picture } & \multicolumn{4}{|c|}{ Stimuli in Experiment 1} \\
\hline & $\begin{array}{l}\text { Frequent } \\
\text { Associate }\end{array}$ & $\begin{array}{c}\text { Same } \\
\text { Semantic } \\
\text { Category }\end{array}$ & $\begin{array}{c}\text { Unrelated } \\
\text { Word }\end{array}$ & $\begin{array}{c}\text { Pronounce- } \\
\text { able Non- } \\
\text { word }\end{array}$ \\
\hline $\begin{array}{l}\text { church } \\
\text { crown } \\
\text { fire } \\
\text { fish } \\
\text { glove } \\
\text { hat } \\
\text { leaf } \\
\text { mouse } \\
\text { rabbit } \\
\text { tree } \\
\text { shoe }\end{array}$ & $\begin{array}{l}\text { priest } \\
\text { king } \\
\text { stove } \\
\text { net } \\
\text { hand } \\
\text { head } \\
\text { rake } \\
\text { cheese } \\
\text { carrot } \\
\text { apple } \\
\text { foot }\end{array}$ & $\begin{array}{l}\text { library } \\
\text { cap } \\
\text { water } \\
\text { lobster } \\
\text { dress } \\
\text { vest } \\
\text { blossom } \\
\text { dog } \\
\text { bear } \\
\text { flower } \\
\text { slipper }\end{array}$ & $\begin{array}{l}\text { slipper } \\
\text { stove } \\
\text { head } \\
\text { flower } \\
\text { blossom } \\
\text { bear } \\
\text { cheese } \\
\text { hand } \\
\text { king } \\
\text { lobster } \\
\text { priest }\end{array}$ & $\begin{array}{l}\text { lorim } \\
\text { gadid } \\
\text { zesam } \\
\text { patek } \\
\text { cokem } \\
\text { mujik } \\
\text { sydah } \\
\text { wydem } \\
\text { pilos } \\
\text { vomer } \\
\text { deray }\end{array}$ \\
\hline & \multicolumn{4}{|c|}{ Stimuli in Experiment 2} \\
\hline Picture & $\begin{array}{l}\text { Frequent } \\
\text { Associate* }\end{array}$ & $\begin{array}{c}\text { Same } \\
\text { Semantic } \\
\text { Category }\end{array}$ & $\begin{array}{l}\text { Unrelated } \\
\text { Word }\end{array}$ & $\begin{array}{l}\text { Pronounce- } \\
\text { able Non- } \\
\text { word }\end{array}$ \\
\hline $\begin{array}{l}\text { bread } \\
\text { chair } \\
\text { hand } \\
\text { man } \\
\text { star } \\
\text { cat } \\
\text { leg } \\
\text { nurse } \\
\text { tiger }\end{array}$ & $\begin{array}{l}\text { butter } \\
\text { table } \\
\text { foot } \\
\text { woman } \\
\text { moon } \\
\text { dog } \\
\text { arm } \\
\text { doctor } \\
\text { lion }\end{array}$ & $\begin{array}{l}\text { meat } \\
\text { lamp } \\
\text { ankle } \\
\text { girl } \\
\text { earth } \\
\text { horse } \\
\text { elbow } \\
\text { banker } \\
\text { bear }\end{array}$ & $\begin{array}{l}\text { ankle } \\
\text { butter } \\
\text { table } \\
\text { earth } \\
\text { elbow } \\
\text { doctor } \\
\text { horse } \\
\text { arm } \\
\text { banker }\end{array}$ & $\begin{array}{l}\text { lorim } \\
\text { zesam } \\
\text { gadid } \\
\text { sydah } \\
\text { cokem } \\
\text { patek } \\
\text { mujik } \\
\text { vomer } \\
\text { deray }\end{array}$ \\
\hline
\end{tabular}

\begin{tabular}{|c|c|c|c|c|c|}
\hline \multirow[b]{2}{*}{ Picture } & \multicolumn{5}{|c|}{ Stimuli in Experiment 3} \\
\hline & $\begin{array}{l}\text { Typical } \\
\text { Category } \\
\text { Member }\end{array}$ & \multicolumn{2}{|c|}{$\begin{array}{l}\text { Atypical } \\
\text { Category } \\
\text { Member }\end{array}$} & $\begin{array}{c}\text { Unrelated } \\
\text { Word }\end{array}$ & $\begin{array}{c}\text { Pronounce- } \\
\text { able Non- } \\
\text { word }\end{array}$ \\
\hline $\begin{array}{l}\text { nurse } \\
\text { policeman } \\
\text { cat } \\
\text { dog } \\
\text { guitar } \\
\text { foot } \\
\text { pants } \\
\text { plane } \\
\text { banana } \\
\text { wagon } \\
\end{array}$ & $\begin{array}{l}\text { teacher } \\
\text { doctor } \\
\text { elephant } \\
\text { lion } \\
\text { trumpet } \\
\text { arm } \\
\text { dress } \\
\text { truck } \\
\text { peach } \\
\text { doll } \\
\end{array}$ & \multicolumn{2}{|c|}{$\begin{array}{l}\text { painter } \\
\text { singer } \\
\text { fox } \\
\text { beaver } \\
\text { accordion } \\
\text { lip } \\
\text { slipper } \\
\text { ship } \\
\text { lime } \\
\text { balloon }\end{array}$} & $\begin{array}{l}\text { ship } \\
\text { dress } \\
\text { trumpet } \\
\text { doctor } \\
\text { elephan } \\
\text { singer } \\
\text { lip } \\
\text { fox } \\
\text { doll } \\
\text { lime }\end{array}$ & $\begin{array}{l}\text { lorim } \\
\text { zesam } \\
\text { gadid } \\
\text { sydah } \\
\text { cokem } \\
\text { patek } \\
\text { vomer } \\
\text { deray } \\
\text { taluk } \\
\text { gemol }\end{array}$ \\
\hline & \multicolumn{5}{|c|}{ Stimuli in Experiment 4} \\
\hline & \multicolumn{2}{|c|}{$\begin{array}{c}\text { Highly } \\
\text { Imageable }\end{array}$} & \multicolumn{2}{|c|}{ Nonimageable } & $\begin{array}{c}\text { Pronounceable } \\
\text { Nonword }\end{array}$ \\
\hline $\begin{array}{l}\text { bed } \\
\text { bird } \\
\text { bread } \\
\text { butterfly } \\
\text { candle } \\
\text { cat } \\
\text { devil } \\
\text { doctor } \\
\text { dog } \\
\text { flower } \\
\text { frog } \\
\text { hand } \\
\text { leg } \\
\text { lion } \\
\text { moon } \\
\text { plane } \\
\text { sink } \\
\text { squirrel } \\
\text { star } \\
\text { violin }\end{array}$ & $\begin{array}{l}\text { autome } \\
\text { banker } \\
\text { elbow } \\
\text { newspa } \\
\text { musicia } \\
\text { poster } \\
\text { iron } \\
\text { jelly } \\
\text { factory } \\
\text { nail } \\
\text { engine } \\
\text { fireplac } \\
\text { avenue } \\
\text { forehea } \\
\text { dirt } \\
\text { candy } \\
\text { arm } \\
\text { alcohol } \\
\text { brain } \\
\text { doll }\end{array}$ & er & $\begin{array}{l}\text { ans } \\
\text { cos } \\
\text { den } \\
\text { law } \\
\text { free } \\
\text { hea } \\
\text { pos } \\
\text { evi } \\
\text { kno } \\
\text { scie } \\
\text { hea } \\
\text { his } \\
\text { cha } \\
\text { dut }\end{array}$ & $\begin{array}{l}\text { er } \\
\text { cracy } \\
\text { om } \\
\text { h } \\
\text { ion } \\
\text { nce } \\
\text { ledge } \\
\text { ce } \\
\text { ng } \\
\text { ry } \\
\text { ce }\end{array}$ & $\begin{array}{l}\text { sydahl } \\
\text { plios } \\
\text { dilyak } \\
\text { mujiket } \\
\text { vomeral } \\
\text { deray } \\
\text { kelhaby } \\
\text { corokam } \\
\text { patek } \\
\text { yolif } \\
\text { loerym } \\
\text { nacul } \\
\text { hallenik } \\
\text { wiblit } \\
\text { naresh } \\
\text { caylid } \\
\text { sezal } \\
\text { zesram } \\
\text { wydene } \\
\text { gadid }\end{array}$ \\
\hline
\end{tabular}

*Frequent associate and same semantic category.

(Received for publication April 11, 1979; revision accepted August 25, 1979.) 